\title{
Autonomous Decision Making Over Reproductive Health Service Utilization and Associated Factors Among Married Women in Illuababora Zone, South West Ethiopia:
}

Dessalegn Nigatu ( $\sim$ dessalegnigatu@gmail.com )

mettu University

Zerihun Bayabil

Zerihun Bayabil (ZB), Mettu Hamlin Fistula Hospital

Tarekegn Fekede

Tarekegn Fekede (TF), Mettu University

Research Article

Keywords:

Posted Date: February 25th, 2022

DOI: https://doi.org/10.21203/rs.3.rs-1369193/v1

License: (c) (i) This work is licensed under a Creative Commons Attribution 4.0 International License.

Read Full License 


\section{Abstract}

Objective $\llbracket$ Assess autonomous decision-making on $\mathrm{RH}$-service utilization and its associated factors among married women in Illubabor zone, South West Ethiopia.

Methods: Community based comparative cross-sectional study was conducted among married women of 584(urban 292 and rural 292) married women of reproductive age group. The data were entered into EPI data version 3.1 and exported to SPSS version 20 computer software for analysis. Both Bivariate and multivariable logistic regression analysis was used. Level of significance was declared at a $p$ value of $<0.05$

Results: A total of 288 in urban and 288 in rural married women were interviewed and yields a response rate of $98.6 \%$ both in urban and rural. Autonomous decision making in urban and rural was $55.2 \%$ [95\% Cl (52.7-64.6)] and 40.3\% [95\% Cl (39.9-52.5)] respectively. In urban, being wives of government employed spouses [AOR 2.102 95\% Cl $(1.16,3.81)$ ], knowledge on $\mathrm{RH}$ [AOR 3.33, 95\% Cl $(1.20,12.49)$ ], above five years in marriage [AOR $1.91,95 \% \mathrm{Cl}(1.19,7.70)]$, were found to be predictors of women's autonomous decision making.

Conclusion: Urban women had better anonymously make decisions than rural on reproductive health service utilization. The study revealed that in urban settings those women who had marriage duration five and more than five years, being wives of government employed spouses had more likely decision making anonymously on reproductive health utilization but not in rural settings. Reproductive health interventions in the area should be promoted by considering empowering of married women on reproductive health service utilization.

\section{Introduction}

Understanding individuals, above all women's reproductive needs and identifying the key factors which influence reproductive negotiation process between husband and wife are necessary to formulate policies aimed at creating conducive environment to improve women's reproductive health, general well-being and their autonomous decision making $(1,2)$.

Reproductive health service utilization is important for the enhancement of both maternal and child health $(3,4)$, despites the fact that the women's right to decide on their own reproductive health issues were mastered by their respective husband (5)Lack of decision autonomous decision making may leads to poor health outcomes, and lack of protective against unsafe sex, STI and gender based violence $(6,7)$

In Ethiopia, there are variations on contraceptive decision autonomous decision making both intra and inter regional states. It is highly exercised in Amhara and lower Somali $54.4 \%$ and $2 \%$ respectively $(8,9)$. Moreover, women's autonomous decision making also differs by their residency area; Urban versus rural residency. For instance, urban women $20 \%$ odds of make a decision than rural(10), urban married women has $55.9 \%$ odds of decision than their rural counterparts(11), in Honduras urban women has $25 \%$ odds of decision than rural(12) and in India urban has $27 \%$ odds of decision than their rural counterparts(13). 
Despite to this, enhancing empowerment status of women contributes best approaches to improve autonomous decision making (14).

Moreover, multiple factors were associated with women autonomous decision making on reproductive health service utilization among those maternal age, socioeconomic status(15), educational status (1619), and limited access to health services(20). In addition the community level autonomy (21), gender based violence (22), being patriarchal society(23) and residency area(24). Consequently, investigating the burden and its determinants of women autonomous decision making on reproductive health service utilization has paramount importance to empower women on their reproductive issues. Therefore, this study aims to identify and compare the magnitude of urban and rural women autonomous decision making on reproductive health service utilization.

\section{Methods \& Materials}

Study design: Community based comparative cross-sectional study was conducted from May to July, 2020 among 584(urban 292 and rural 292) married women of reproductive age group.

Study population: All randomly selected married women in reproductive age group (15-49 years of age), who were resident of Dupa Town and surrounding rural kebele.

Study unit: Randomly selected married women in reproductive age group (15-49 years of age), who actually participate to the study were the study unit.

Inclusion criteria: Women in a marriage or consensual union and lived at least for six months in the area were included in the study.

\section{Sample size determination}

Sample size was determined using Epi INFO version 7 considering the following assumptions: level of significance (0.05), autonomous decision making (0.80) Proportion of rural married women autonomous decision making on contraceptive use $\mathrm{p}=43.1 \%$ and urban married women decision autonomous decision making on contraceptive use $p=55.9 \%$ ) (22)With the consideration of non-response rate of $15 \%$, this yielded a total sample of 584 Urban (292) and rural (292).

\section{Sampling technique}

Census was conducted in urban area (Dupa town) which is found in Darimu district, married women enumeration was carried out to identified married women of reproductive age group in area were the study was employed. In order to generate sampling frame, In rural area total number of married women of child bearing age group obtained from the family folder of the community health information system (CHIS) available at health post and record number, Then recoding the record number lists in ascending order to 
make a frame and use table of random numbers to identify study participants. Based on these 2201 married women were identified from Dupa town and surrounding three rural kebeles, the three surrounding rural kebeles were selected randomly from the total of nine (9) surrounding rural kebeles within $10 \mathrm{~km}$ radius of the town health center, proportion allocation for the three surrounding rural kebeles was based on number their married women of reproductive age group.

In this respect, from both urban and rural area the eligible identified married women of childbearing age were interviewed with simple random sampling technique, until the number of sample populations completed. In some conditions like married women of reproductive age group were away from home, the interviewer re-visited the household at least three times and if failed to get the respondent, it was excluded from the survey and noted as non- response.

\section{Measurement}

Structured questionnaire was used for interviewing selected participants. Four questions were used to construct composite score on autonomous decision making over RH-care service utilization. Based on these the women were asked "who in her family usually has the final say on the following decisions: 1.Skilled birth 2, antenatal care (ANC), 3, post-natal care (PNC) and 4.Modern contraceptive use. For each items the response was scored as: 2 if a woman made sole decision, 1 if she was involved with someone (husband/partner or someone else) and 0 otherwise; For non-users of modern contraceptives and ANC; if their main reason for non-use is opposition from others (husband, mother in law, relative, religion etc.) the value was assigned as 0 and 1 if otherwise. Eventually, married women decision-making on RH service utilization among study units was set as binary outcome variable by merging the two groups of women together those scored above the mean categorized as higher autonomous decision making whereas those who score less than mean score categorized as women with low decision autonomous decision making on $\mathrm{RH}$ care service utilization after developing mean score independently for each. [10, 20,31].

Women knowledge of $\mathrm{RH}$-service was assessed by considering knowledge regarding the components of $\mathrm{RH}$ - services essentially that addresses services such as modern contraceptive, safe child bearing, reproductive tract infections, cancers, sexually transmitted infections. HIV/AIDS, safer sexual behavior and key danger signs during labor and childbirth. The desired answer was coded as 1 , otherwise 0 . Totally 40 questions were asked to assess knowledge on $\mathrm{RH}$, therefore, those mothers who scored above $70 \%(\geq 28)$ were knowledgeable, less knowledgeable otherwise [20].

\section{Data collection procedure}

The data were collected using semi structured pre tested questionnaire. The questionnaire was prepared in English then translated to Afan Oromo then back to English by different language expertise. The data were collected using interviewer administered questionnaire to feet majority of the respondent's characteristics. 
The study subjects were interviewed about their reproductive health service utilization history and sociodemographic variables, autonomous decision making on $\mathrm{RH}$-care service utilization.

\section{Data quality management}

Data collection instrument was developed after thoroughly revising related literatures and adopting questionnaires used in other similar studies by considering local conditions. The English version of the questionnaire translated to Afan Oromo/ naïve local language/ and translated back to English to check consistency by language expert. Before the actual data collection, the questionnaire was pre-tested on $5 \%$ of similar populations which reside in other adjacent district (Alge Sachi) not included in the survey and necessary modifications was made specifically on the understandability of specific item. Six Midwife nurse local language naïve data collectors \& One Supervisor were recruited for actual data collection.

One day training was given to data collectors and supervisors. Completeness and consistency of the collected data was reviewed and checked every day by supervisors. Discussions were made with the interviewers at the end of the day and in the morning; corrective actions was taken timely to minimize errors committed during interview.

\section{Data Entry and Analysis}

The collected data were cleaned, edited, coded and entered into Epi data version 3.1 then exported to Statistical package for social sciences (SPSS) version 21.0. Descriptive analysis was carried out for each of independent variables. Multivariable Logistic regression model was used and variables with $p$-value less than 0.25 with bivariate analysis were entered into multivariable logistic regression; variables with $p$ value less than 0.05 at $95 \%$ Confidence interval were declared as statistically significant with outcome variable. Adjusted Odds ratio was used to test the degree of association and Goodness of fit of the final model was checked using Hosmer Lemeshow test of goodness of feet considering good model fitness at P-value > 0.05(0.664), Omnibus likelihood test $<0.05(0.000)$.

\section{Ethical approval and participants' informed consent}

Ethical approval was given by the Institutional Review Board (IRB) of Mettu University Research Ethics Committee (Reference: ID 4275/2020). Written or recorded verbal informed consent was obtained from the participants, by the interviewer, immediately prior to the interview

All methods were carried out in accordance with relevant guidelines and regulations and Social Care Research and the Declaration of Helsinki.

\section{Results}




\section{Socio-demographic Characteristics of the Respondents}

A total of 576 (urban 288 and rural 288) women were participated in the study making the response rate98.6\%. The mean (+ SD) age of the respondent was $30.24( \pm 7.02)$ in the urban and $31.3( \pm 7.24)$ rural respectively. In both categories, the large numbers of respondents were found in the age group of 25$34 y e a r s$. Most of the respondents were house wife $(76.4 \%)$ in the urban and $(96.2 \%)$ in the rural, one hundred thirty four $(46.5 \%)$ in the urban and one hundred fifty nine $(55.2 \%)$ in the rural was attended primary education (table 1 ).

Table 1

Socio-demographic variables of married women of reproductive age group in urban and rural of Darimu, South-West Ethiopia, 2020

Others, gurage*Tigrea*, other, Jehovah**

\section{Reproductive health characteristics}

In urban two hundred thirty seven married women (82.3\%) and one hundred eighty seven rural women $(64.9 \%)$ were knowledgeable. Near to one third of the respondents in urban $29.9 \%$ had history of first marriage age greater than twenty years and in rural (30.2\%) was married at the age between sixteen to nineteen years. In urban women 129(42.4\%), whereas 116(37.8\%) in rural had 2-3 children. One hundred

seventeen (29.5\%) urban women and one hundred fourteen (19.8) of rural women were heard components of reproductive health, (Table 2 )

Table 2

Demographic-characteristics and Reproductive health knowledge of married women of reproductive age group in Dupa town and surrounding kebeles, South-West Ethiopia, 2020 


\begin{tabular}{|c|c|c|c|}
\hline \multicolumn{2}{|c|}{ Characteristics $\quad$ Category } & $\begin{array}{l}\text { Urban } \\
\mathrm{N}(\%)\end{array}$ & $\begin{array}{l}\text { Rural } \\
\mathrm{N}(\%)\end{array}$ \\
\hline \multirow{4}{*}{ Age category } & & & \\
\hline & $15-24$ & $70(24.3)$ & $65(22.6)$ \\
\hline & $25-34$ & $121(42)$ & $142(49.3)$ \\
\hline & $35-49$ & $97(33.7)$ & $81(28.1)$ \\
\hline \multirow[t]{3}{*}{ Ethnicity } & Oromo & $200(69.4)$ & 211(73.3) \\
\hline & Amhara & $76(26.4)$ & 63(21.9) \\
\hline & Others* & $12(4.2)$ & $14(4.5)$ \\
\hline \multirow[t]{4}{*}{ Religion } & Orthodox & $75(26)$ & $43(14.9)$ \\
\hline & Muslin & $158(54.9)$ & $181(62.8)$ \\
\hline & Protestant & $51(17.7)$ & $62(21.5)$ \\
\hline & Other** & $4(1.4)$ & $2(0.7)$ \\
\hline \multirow{4}{*}{$\begin{array}{l}\text { Educational status of } \\
\text { respondent }\end{array}$} & Unable to read and write & $36(12.5)$ & $51(17.7)$ \\
\hline & Primary education & $134(46.5)$ & $159(55.2)$ \\
\hline & Secondary education & $95(33)$ & $74(25.7)$ \\
\hline & Higher education & $23(8)$ & $4(1.4)$ \\
\hline \multirow{4}{*}{$\begin{array}{l}\text { Educational status of } \\
\text { husbands }\end{array}$} & Unable to read and write & $28(9.7)$ & $37(12.8)$ \\
\hline & Primary education & $142(49.3)$ & $185(64.2)$ \\
\hline & Secondary education & $92(31.9 \%)$ & $61(21.1)$ \\
\hline & Higher education & $26(9)$ & $5(1.7)$ \\
\hline \multirow[t]{3}{*}{ Occupation of respondent } & Governmental employee & $23(8)$ & $7(2.4)$ \\
\hline & Merchant & $45(15.6)$ & $4(1.4)$ \\
\hline & House wife & $220(76.4)$ & $277(96.2)$ \\
\hline
\end{tabular}




\begin{tabular}{|c|c|c|c|}
\hline \multirow[t]{2}{*}{ Characteristics } & \multirow[t]{2}{*}{ Category } & Urban & Rural \\
\hline & & $\mathrm{N}(\%)$ & $\mathrm{N}(\%)$ \\
\hline \multirow[t]{2}{*}{ Knowledge of $\mathrm{RH}$} & Knowledgeable & $237(82.3)$ & $187(64.9)$ \\
\hline & Not knowledgeable & $51(17.7)$ & 101(35.1) \\
\hline \multirow[t]{3}{*}{ Age of first marriage } & $<16 y e a r s$ & $5(1.7)$ & $9(3.1)$ \\
\hline & 16-19years & $104(36.1)$ & 172(59.7) \\
\hline & $>20 y e a r s$ & $179(62.2)$ & 107(37.2) \\
\hline \multirow[t]{3}{*}{ Number of children } & 1-2years & $55(19.1)$ & $57(19.8)$ \\
\hline & 2-3years & $123(42.7)$ & 109(37.8) \\
\hline & $>$ 5years & $110(38.1)$ & $122(42.4)$ \\
\hline \multirow[t]{2}{*}{ Birth interval } & 1-2year & 195(67.7) & 201(69.8) \\
\hline & 3-5years & $93(32.3)$ & $87(30.2)$ \\
\hline \multirow[t]{3}{*}{ Duration of marriage } & 1-2years & $12(4.2)$ & $19(6.6)$ \\
\hline & 3-4years & $93(32.3)$ & $86(29.9)$ \\
\hline & $>$ 5years & 183(63.5) & 183(63.5) \\
\hline
\end{tabular}

\section{Source of Reproductive health information}

More than fifty presents of the respondents in urban and rural area their source of information about reproductive health was health extension workers $60.2 \%$ in urban and $53.1 \%$ in rural (Table 3 ).

Table 3

Source of reproductive health information among married women of reproductive age group in Illubabor zone, Dupa town and surrounding kebele, South-West Ethiopia, 2020 


\begin{tabular}{|lll|}
\hline Variables & Urban (\%) & Rural (\%) \\
\hline Health extension workers & & \\
\hline Yes & $175(60.2)$ & $153(53.1)$ \\
\hline No & $113(39.2)$ & $135(46.9)$ \\
\hline Other health professional & & \\
\hline Yes & $139(47.8)$ & $92(28.1)$ \\
\hline No & $149)(48.2)$ & $196(31.9)$ \\
\hline Radio or Television & & \\
\hline Yes & $74(25.7)$ & $22(7.6)$ \\
\hline No & $224(73.6)$ & $266(92.4)$ \\
\hline Peer & & \\
\hline Yes & $106(63.2)$ & $42(14.6)$ \\
\hline No & $182(36.9)$ & $246(85.4)$ \\
\hline Husbands & & \\
\hline Yes & $38(13.2)$ & $14(4.9)$ \\
\hline No & $250(86.8)$ & $274(95.1)$ \\
\hline Others & $284(98.6)$ & $286(99.3)$ \\
\hline Yes & & \\
\hline No & & \\
\hline
\end{tabular}

Other, Books and school*

\section{Level of autonomous decision making over reproductive health service utilization}

The study showed that, autonomous decision making on reproductive health service utilization among married women in the study area urban and rural 159(55.2\%) and 116(40.3\%) respectively had autonomous decision making over reproductive health service utilization (Table 4).

Table 4

level of autonomous decision making on $\mathrm{RH}$-service utilization among urban and rural married women in

Dupa town and surrounding rural kebeles, south west Ethiopia, 2020. 


\begin{tabular}{|llll|}
\hline Settings & Decisions on & Lower decision & Higher decision \\
\hline Urban & RH-care utilization & $129(44.8 \%)$ & $159(55.2 \%)$ \\
\hline Rural & RH-care utilization & $172(59.7 \%)$ & $116(40.3 \%)$ \\
\hline
\end{tabular}

\section{Factors affecting autonomous decision making of married women}

Bivariate analysis reveals: attending formal education of respondents and husbands, husband occupation, women occupation, knowledgeable about $\mathrm{RH}$, and more than five years marriage duration shows statistical significant association for both urban and rural settings (Table 5).

In the multivariable logistic regression: urban attending formal education of respondent, being knowledgeable about RH and duration of marriage, occupation of husband and for rural women Rhknowledge and formal education of husband were found to be significant of women autonomous decision making on $\mathrm{RH}$ service utilization(Table 5).

\section{Table 5}

Factors affecting married women autonomous decision making on reproductive health service utilization ,Illubabor Zone, Darimu district, urban and rural resident south west Ethiopia, 2020. 


\begin{tabular}{|c|c|c|c|c|c|}
\hline \multirow{3}{*}{ Setting } & \multirow{3}{*}{ Variables } & \multicolumn{2}{|c|}{$\begin{array}{l}\text { autonomous decision } \\
\text { making }\end{array}$} & \multirow{3}{*}{ COR (95.0\% C.I) } & \multirow{3}{*}{ AOR (95.0\% C.I) } \\
\hline & & Lower & Higher & & \\
\hline & & $\mathrm{N}(\%)$ & $N(\%)$ & & \\
\hline \multirow[t]{4}{*}{ Urban } & $\begin{array}{l}\text { Education of } \\
\text { respondent }\end{array}$ & & & & \\
\hline & $\begin{array}{l}\text { Unable to } \\
\text { read \& write }\end{array}$ & $35(92.2 \%)$ & $1(2.8 \%)$ & 1 & 1 \\
\hline & Primary (1-8) & $158(69 \%)$ & $71(31 \%)$ & $.063[.060, .419]^{\star}$ & $0.045[.003, .62]^{\star}$ \\
\hline & $\begin{array}{l}\text { Secondary }(9+) \\
\& \text { above }\end{array}$ & $6(26 \%)$ & 17(73.9(\%) & $.010\left[.001, .091^{\star}\right]$ & $\begin{array}{l}0.434[.079 \\
.385]^{\star}\end{array}$ \\
\hline \multirow[t]{4}{*}{ Rural } & $\begin{array}{l}\text { Education of } \\
\text { respondent }\end{array}$ & & & & \\
\hline & $\begin{array}{l}\text { Unable to } \\
\text { read \& writ }\end{array}$ & $28(66.7)$ & 14(33.3\%) & 1 & 1 \\
\hline & Primary (1-8) & $79(58.1)$ & $57(41.9 \%)$ & $.69[.252, .734]^{\star}$ & $2.64[.685,3.27]$ \\
\hline & $\begin{array}{l}\text { Secondary }(9+) \\
\& \text { above }\end{array}$ & $32(41.6)$ & $45(58.4)$ & $.35[.210, .989]^{\star}$ & $1.93[.961,3.91]$ \\
\hline \multirow[t]{4}{*}{ Urban } & $\begin{array}{l}\text { Education of } \\
\text { husband }\end{array}$ & & & & \\
\hline & $\begin{array}{l}\text { Unable to } \\
\text { read \& write }\end{array}$ & $12(44.4 \%)$ & $15(55.6 \%)$ & 1 & - \\
\hline & Primary (1-8) & $99(44.8 \%)$ & $122(91.7 \%)$ & $0.11[.22,0.583]^{\star}$ & - \\
\hline & $\begin{array}{l}\text { Secondary }(9+) \\
\& \text { above }\end{array}$ & $2(8.3 \%)$ & $22(91.7 \%)$ & $0.11[.26,0.488]^{\star}$ & \\
\hline \multirow[t]{4}{*}{ Rural } & $\begin{array}{l}\text { Education of } \\
\text { husband }\end{array}$ & & & & \\
\hline & $\begin{array}{l}\text { Unable to } \\
\text { read \& write }\end{array}$ & $36(97.3 \%)$ & $1(2.7 \%)$ & 1 & \\
\hline & Primary (1-8) & $221(89.8 \%)$ & $25((10.2)$ & $.024[.001,0.134]^{\star}$ & $.018[.002, .23]^{\star}$ \\
\hline & $\begin{array}{l}\text { Secondary } \\
(9+) \& \text { above }\end{array}$ & $1(20 \%)$ & $4(80 \%)$ & $.006[.003,0.263]^{\star}$ & $.004[.001, .098]^{\star}$ \\
\hline \multirow[t]{2}{*}{ Urban } & $\begin{array}{l}\text { Occupation of } \\
\text { husbands }\end{array}$ & & & & \\
\hline & Farmer & $30(19.6 \%)$ & $123(80 \%)$ & 1 & 1 \\
\hline
\end{tabular}




\begin{tabular}{|c|c|c|c|c|c|}
\hline & Merchants & $16(76.2 \%)$ & $5(23.8 \%)$ & $13.12[4.45,38.65]^{\star}$ & $3.386[.564,20.32]$ \\
\hline & $\begin{array}{l}\text { Government } \\
\text { employee }\end{array}$ & $43(37.7 \%)$ & $71(62.3 \%)$ & $2.483[1.432,4.30] *$ & $\begin{array}{l}2.102(1.16 \\
3.81]^{\star}\end{array}$ \\
\hline \multirow[t]{4}{*}{ Rural } & $\begin{array}{l}\text { Occupation of } \\
\text { husbands }\end{array}$ & & & & \\
\hline & Farmer & $94(59.1)$ & $65(40.9)$ & 1 & 1 \\
\hline & Merchants & $44(48.9)$ & $46(51.1)$ & $.661[.23,0.90]^{\star}$ & $1.01[.252,1.47]$ \\
\hline & $\begin{array}{l}\text { Government } \\
\text { employee }\end{array}$ & $1(16.7 \%)$ & $5(83.3)$ & $.138[.16,0.211]^{\star}$ & $2.06[.192,2.24]$ \\
\hline \multirow[t]{3}{*}{ Urban } & $\begin{array}{l}\text { Duration of } \\
\text { marriage }\end{array}$ & & & & \\
\hline & $<5$ years & $84(80 \%)$ & $21(20 \%)$ & $.42[0.24,0.74]^{\star}$ & $1.94[1.19,7.20]^{*}$ \\
\hline & $>$ 5years & $115(62.8 \%)$ & $68(37.2 \%)$ & 1 & 1 \\
\hline \multirow[t]{3}{*}{ Rural } & $\begin{array}{l}\text { Duration of } \\
\text { marriage }\end{array}$ & & & & \\
\hline & $<5$ years & $176(87.6 \%)$ & $25(12.4 \%)$ & $2.33[1.56,5.30]^{\star}$ & $1.04[0.36,2.99]$ \\
\hline & $>$ 5years & $82(94.35)$ & $5(5.7 \%)$ & 1 & 1 \\
\hline \multirow[t]{3}{*}{ Urban } & Knowledge & & & & \\
\hline & Knowledgeable & $57(56.4 \%)$ & $44(43.6 \%)$ & 1 & 1 \\
\hline & Not Knowledge & $32(17.1 \%)$ & $155(82.9)$ & $.159[0.92,0.27]^{\star}$ & $3.33[1.20,12.49]^{\star}$ \\
\hline \multirow[t]{3}{*}{ Rural } & Knowledge & & & & \\
\hline & Knowledge & $22(43.1)$ & $29(56.9)$ & 1 & 1 \\
\hline & Not Knowledge & $8(3.4)$ & $229(96.4)$ & $.046[.019,0.113]^{\star}$ & $4.08[5.27,14.02]^{\star}$ \\
\hline
\end{tabular}

AOR, Adjusted odds ratio, COR, crud Odds ratio, statistically significant at P-value $<0.05^{\star}$

159(55.2\%) with [95\% Cl (52.7-64.6)] of urban currently married women had higher autonomous decision making on reproductive health service utilization compared to $116(40.3 \%)$ with [95\% $\mathrm{Cl}(39.9-52.5)]$ of married women in rural area. In urban being wives of government employed husband two times odds of [AOR 2.102, 95\% Cl $(1.16,3.81)$ ], duration of marriage more than five years were about two times [AOR $1.91,95 \% \mathrm{Cl}(1.19,7.70)$ ] and being knowledgeable on $\mathrm{RH}$ were three time odds of [AOR $3.33,95 \% \mathrm{Cl}$ $(1.20,12.49)]$ decision autonomous decision making on reproductive health service utilization and Married women who had formal education were less likely autonomous decision making over Reproductive health service utilization. Whereas, in rural area having Reproductive health knowledge were four times [AOR 4.08, 
95\% C.I $(5.27,14.02)]$ less likely autonomous decision making over RH-service utilization and being wives of formal educated husband were less likely to be autonomous decision making over Rh-health service utilization(Table 5).

\section{Discussion}

This study showed that Women in urban setup had greater autonomous decision making over reproductive health service utilization than the rural counterpart. 159(55.2\%) with [95\% $\mathrm{Cl}$ (52.7-64.6)] of urban currently married women had higher autonomous decision making on reproductive health service utilization compared to $116(40.3 \%)$ with [95\% $\mathrm{Cl}$ (39.9-52.5)] of married women in rural area(22). The variation might be due to the fact that, in most parts of rural Ethiopia, women usually attained low education; low involvement in their healthcare decisions than urban women.

The finding of urban married women autonomous decision making is comparable with a cross sectional study conducted in southern Ethiopia, autonomous decision making on contraception use found that, 53.8\% (25)and in Amhara region 54.4\% (26). Higher than other mutual consent for contraceptive use, such as in (27), 30.7\%, study done in Bangladesh 35\%(28) incomparable with Ethiopian Somalia region mutual consent for contraceptive use (2\%) (29).

The finding of rural married women autonomous decision making has similarity with a cross sectional study conducted in Bale found that, $39.5 \%$ regarding maternal and child health care decision (30) consistent with southern Ethiopia rural women autonomous decision making over contraceptive use 43.1\%(31). Higher than the study conducted in Bangladesh 35\% [11)], SNNPR 30.7\% [9], Honduras 25\% [12], Malawi 28.75\% [32] And Pakistan $28 \%$ [33].The variation might be from Social factors and cultural difference contributes on autonomous decision making on $\mathrm{RH}$-service utilization.

The finding of this study is lower in both urban and rural settings when compared with the cross sectional studies from Southern Ethiopia on married women that, $64.8 \%$ of urban women had autonomous decision making over contraceptive use [16]. The Ethiopian national level study that revealed $71.6 \%$ of rural women participate in own health care decisions [34]. This might be due to this study added other different components of $\mathrm{RH}$ components as composite variables. This discrepancy might be due to the fact that this study considered both rural and urban women in one district, whereas others might be regional, urban or rural. It might also be due to the difference in educational status, and cultural norms of the women in the study settings.

This study also revealed that, being wives of government employed spouses in urban, more likely to deiced over RH service utilization than their counterparts, the finding of the study were comparably similar with the cross sectional study done in Mizan- Aman, being wives of government employed spouses were two times more likely to decide on family planning use [17].

This study revealed that urban married women who had formal education were less likely to decide over reproductive health service utilization than counterpart. The finding of this study were comparably lower 
than the study conducted in East Wollega Zone, January, 2015,reveled than those respondents had formal education were more likely to decide on ANC[14] and Honduras[12]. Variation of the study could be Ethiopia, strong cultural and traditional backgrounds can influence, regarding women formal education.

This study also revealed that, being wives of husbands who had formal education were less likely to women's autonomous decision making in rural area those with husband did not had formal education. This study were comparably lower than, study conducted in Mizan-Aman, South Ethiopia, Women whose husbands had attended formal education were more likely to have a decision as compared to their counter parts[17].

This study revealed that urban women those in marital union for five and more were more likely to be higher autonomous decision making on RH service utilization than those who stay less than five years in marital union. This finding was consistent with study from Nekemte, West Ethiopia; which reports that women with more than five years duration were more likely to be decision maker than those who were in marital union less than five (32)

The study also indicated that both urban and rural married women were knowledgeable about $\mathrm{RH}$ components had three times in urban and four folds in rural had more likely to diced over reproductive health service utilization than those who had not knowledgeable. This finding is higher when comparing with study conducted in Gedo zone, revealed that, married women knowledgeable on contraceptive were decide two times more likely to than lowly knowledgeable [35]. This variation might be from socio cultural difference.

\section{Conclusion}

Urban-rural difference was found in the study area on autonomous decision making of reproductive health service utilization. Urban women had better autonomous decision making to make decisions on reproductive health service utilization than rural women. The study revealed that in urban settings those women who had marriage duration five and more than five years, being wives of government employed spouses had more likely autonomous decision making on reproductive health utilization but not in rural settings, in both settings urban and rural, married women were knowledgeable about RH components had more likely to autonomous decision making over reproductive health service utilization than those who had not knowledgeable. Hence, public health interventions targeting married women should be implemented.

\section{Abbreviations}

ANC: ante-natal care, DHS: demographic health survey, HFD: health facility delivery; ICPD: international conference on population and development, IEC: information, education and communication, IRC: international rescue committee, LAM: lactating amenorrhea methods, $\mathrm{MCH}$ : maternal and child health, PNC: post-natal care, RH: reproductive health SDG: sustainable development goals, SPSS: statistical 
package for social science, SRH: sexual and reproductive health, STDS: sexually transmitted diseases, STI: sexually transmitted infections.

\section{Declarations}

\section{Availability of Data and material}

The datasets used and/or analyzed during the current study available from the corresponding author on reasonable request. The original data is available from Action for M.E. in an excel spreadsheet.

\section{Data sharing}

The original data is available with corresponding author on reasonable request.

\section{Ethical Declaration}

Ethical approval was given by the Institutional Review Board (IRB) of Mettu University Research Ethics Committee (Reference: ID 4275/2020). Written or recorded verbal informed consent was obtained from the participants, by the interviewer, immediately prior to the interview.

\section{Funding}

No funding was obtained for this study

\section{Consent for publication}

Not applicable.

\section{Authors' contributions}

Conceived and designed by ZB, DN and TF. ZB performed data analysis and interpreting of findings. DN prepares manuscript. All the authors read and approved the final manuscript

\section{Competing interests}

The Authors declare that they have no competing interests

\section{Acknowledgments}


The authors would like to acknowledge Mettu University for giving this research project. We would like to thank data collectors and supervisors. Finally, we thank volunteers for their involvement in this study project.

\section{References}

1. Li X. Gender relations and reproductive decision-making in the context of rural china in the postreform period. ISS Working Paper Series/General Series. 1999;284:1-76.

2. Santhya K, Jejeebhoy SJ. Sexual and reproductive health and rights of adolescent girls: Evidence from low-and middle-income countries. Global public health. 2015;10(2):189-221.

3. Stephenson R, Baschieri A, Clements S, Hennink M, Madise N. Contextual influences on the use of health facilities for childbirth in Africa. American journal of public health. 2006;96(1):84-93.

4. Kesterton AJ, Cleland J, Sloggett A, Ronsmans C. Institutional delivery in rural India: the relative importance of accessibility and economic status. BMC pregnancy and childbirth. 2010;10(1):1-9.

5. Shahjahan M, Mumu SJ, Afroz A, Chowdhury HA, Kabir R, Ahmed K. Determinants of male participation in reproductive healthcare services: a cross-sectional study. Reproductive health. 2013;10(1):1-6.

6. Moyer CA, Mustafa A. Drivers and deterrents of facility delivery in sub-Saharan Africa: a systematic review. Reproductive health. 2013;10(1):1-14.

7. Wado YD, Afework MF, Hindin MJ. Unintended pregnancies and the use of maternal health services in southwestern Ethiopia. BMC international health and human rights. 2013;13(1):1-8.

8. Performance Monitoring A. Project Makerere University School of Public Health. Detailed indicator report: Uganda. 2014.

9. Furuta M, Salway S. Women's position within the household as a determinant of maternal health care use in Nepal. International family planning perspectives. 2006:17-27.

10. Ghose B, Feng D, Tang S, Yaya S, He Z, Udenigwe O, et al. Women's decision-making autonomy and utilisation of maternal healthcare services: results from the Bangladesh Demographic and Health Survey. BMJ open. 2017;7(9).

11. Tadel A, Tesfay A, Kebede A. Decision makingautonomous decision making on reproductive health and rights and associated factors among married women in mettu rural district, south west Ethiopia 2017.

12. Hall MG, Garrett JJ, Barrington C. La situacion economica: social determinants of contraceptive use in rural Honduras. Global public health. 2014;9(4):455-68.

13. Donnelly KZ, Foster TC, Thompson R. What matters most? The content and concordance of patients' and providers' information priorities for contraceptive decision making. Contraception. 2014;90(3):280-7.

14. Rahman MM, Mostofa MG, Hoque MA. Women's household decision-making autonomy and contraceptive behavior among Bangladeshi women. Sexual \& Reproductive Healthcare. 2014;5(1):9- 
15.

15. Tiruneh FN, Chuang K-Y, Chuang Y-C. Women's autonomy and maternal healthcare service utilization in Ethiopia. BMC health services research. 2017;17(1):1-12.

16. James-Hawkins L, Peters C, VanderEnde K, Bardin L, Yount KM. Women's agency and its relationship to current contraceptive use in lower-and middle-income countries: A systematic review of the literature. Global Public Health. 2018;13(7):843-58.

17. Prata N, Tavrow P, Upadhyay U. Women's empowerment related to pregnancy and childbirth: introduction to special issue. BMC pregnancy and childbirth. 2017;17(2):1-5.

18. Garcia ER, Yim IS. A systematic review of concepts related to women's empowerment in the perinatal period and their associations with perinatal depressive symptoms and premature birth. BMC pregnancy and childbirth. 2017;17(2):1-13.

19. Bisika T. Cultural factors that affect sexual and reproductive health in Malawi. BMJ Sexual \& Reproductive Health. 2008;34(2):79-80.

20. Melo J, Peters M, Teal S, Guiahi M. Adolescent and young women's contraceptive decision-making processes: choosing "The Best Method for Her". Journal of pediatric and adolescent gynecology. 2015;28(4):224-8.

21. Downey MM, Arteaga S, Villaseñor E, Gomez AM. More than a destination: contraceptive decision making as a journey. Women's health issues. 2017;27(5):539-45.

22. Bogale B, Wondafrash M, Tilahun T, Girma E. Married women's decision makingautonomous decision making on modern contraceptive use in urban and rural southern Ethiopia. BMC public health. 2011;11(1):1-7.

23. Ledger S, Earle S, Tilley E, Walmsley J. Contraceptive decision-making and women with learning disabilities. Sexualities. 2016;19(5-6):698-724.

24. Ahmed S, Creanga AA, Gillespie DG, Tsui AO. Economic status, education and empowerment: implications for maternal health service utilization in developing countries. PloS one. 2010;5(6):e11190.

25. Adhikari R. Effect of Women's autonomy on maternal health service utilization in Nepal: a cross sectional study. BMC women's health. 2016;16(1):1-7.

26. Semahegn A, Belachew T, Abdulahi M. Domestic violence and its predictors among married women in reproductive age in Fagitalekoma Woreda, Awi zone, Amhara regional state, North Western Ethiopia. Reproductive health. 2013;10(1):1-9.

27. Habte F, Demissie M. Magnitude and factors associated with institutional delivery service utilization among childbearing mothers in Cheha district, Gurage zone, SNNPR, Ethiopia: a community based cross sectional study. BMC pregnancy and childbirth. 2015;15(1):1-12.

28. Rahman M, Nakamura K, Seino K, Kizuki M. Intimate partner violence and use of reproductive health services among married women: evidence from a national Bangladeshi sample. BMC public health. 2012;12(1):1-12. 
29. Zepro NB, Ahmed AT. Determinants of institutional delivery service utilization among pastorals of Liben Zone, Somali Regional State, Ethiopia, 2015. International journal of women's health. 2016;8:705.

30. Takele A, Degu G, Yitayal M. Demand for long acting and permanent methods of contraceptives and factors for non-use among married women of Goba Town, Bale Zone, South East Ethiopia. Reproductive health. 2012;9(1):1-11.

31. Delbiso TD. Genderautonomous decision making relations in reproductive decision-making: The case of migrant weavers of Addis Ababa, Ethiopia. Journal of Science \& Development. 2014;2(1):59-71.

32. Melka AS, Tekelab T, Wirtu D. Determinants of long acting and permanent contraceptive methods utilization among married women of reproductive age groups in western Ethiopia: a cross-sectional study. Pan African Medical Journal. 2015;22(1). 